\title{
Research on Educational Equity and Compensation Strategies After the End of the Covid-19
}

\author{
Chao Dong*, Jing Liu, Jing Jiang, Yu Liu \\ School of International Education, Nanjing Institute of Technology \\ *Corresponding author.Chao Dong. Email: knjy@njit.edu.cn
}

\begin{abstract}
The Covid-19 has changed the original education and teaching methods, causing traditional offline education to migrate to online. Due to the limitations of online education methods and education carriers, factors such as the level of regional development, family environment, and individual differences in students have led to a balanced and balanced education. The issue of fair development is highlighted. When colleges and universities face major public health emergencies, how can innovations in educational technology and educational methods make up for educational losses, especially when the educational differences between regions and families cannot be made up in a short period of time. Compensation for education. Therefore, colleges and universities should take educational equity as the premise and the innovative development of education as the goal. Through the integration and innovation of online and offline education models, the guidance and growth support activities based on individual differences of students, the overall construction of "quality based on fairness, and quality for fairness". There is a new system of education governance with quality, fairness and quality.
\end{abstract}

Keywords: Online teaching, Education equity, Education compensation.

\section{RESEARCH BACKGROUND}

Education, as the most important channel to break class solidification and realize personal value, magnifies its unfairness and social structural problems to a certain extent during the online teaching period. Taking the author's university as an example, according to a survey of 500 students' online learning situation, $3.09 \%$ of students could not find the course entrance and teaching resources in time, and the live teaching was forced to be interrupted due to network problems, which was as high as $22.68 \%$. A survey conducted by the China Rural Education Development Research Institute of Northeast Normal University on 252,000 students across the country showed that $5.98 \%$ of the students were unable to follow the course schedule [1]. The loss is not limited to the level of professional learning. The education scene of "school as a unit" is lost. Students' ideological and political education, mental health education, second- class activities, internship practice, and job hunting have lost their grasp and bond. The degree of family digitization, the learning environment and even the educational level of the parents, and the degree of economic development in the area where the students are located have become important factors that determine the phased growth of students, and schools are weakened by the leading role of education. Currently in China, schools are returning to normal teaching management order. It is necessary for colleges and universities to evaluate the quality of education and the process of student growth during online teaching, provide more targeted support services for students' learning and growth, and adopt a series of compensations. Strategies to promote education equity and quality improvement. 


\section{A SUMMARY OF RESEARCHES ON EDUCATIONAL EQUITY}

The concept of fairness in education is fully elaborated in the "Education Law of the People's Republic of China". In a nutshell, citizens have equal opportunities to receive education in accordance with the law. The right to equality in education includes equality in educational content, equal opportunities for education, and equality in the enjoyment of educational resources provided by the state [2]. From the perspective of education implementation process, education fairness can be summarized as starting point fairness, process fairness and result fairness. In China, the connotation of education equity is constantly changing and extending along with the evolution from elite education to popular education. At the stage of elite education, more emphasis is placed on the fairness of the starting point of education, that is, everyone has the right to education. In the new era, education equity has been explained and implemented more comprehensively. The report of the 19th National Congress of the Communist Party of China pointed out that it is necessary for every child to enjoy fair and quality education, promote education fairness, and cultivate socialist builders and successors with comprehensive development of moral, intellectual, physical, and artistic. "Fair and quality education" interprets the new connotation of educational equity. It not only refers to the fairness of the starting point of education, but also refers to the process of education [3], that is, everyone can be treated equally during the process of receiving education. Enjoy the same educational resources, and at the same time have employment opportunities and development prospects in line with their own professional positioning and career development in terms of educational results, so education equity runs through the entire process of education.

Internationally, the definition of equality and fairness can be traced back to the works of Aristotle [4] and Plato [5] in the West and Confucius in China [6]. Today, the idea of equality and fairness has been developed into a variety of theoretical methods, focusing on these concepts from different angles [7]. The literature dealing with the issue of educational equality in the Chinese context is usually empirical, taking the concept of inequality as known [8] and helping to explain educational inequality Causes and solutions. However, the policy analysis of equality and fairness seems to be much more complicated [9]. Many policy documents or research reports have emphasized the importance of education fairness and warned educators not to pay attention to the possible consequences of these problems in education management. For example, in elementary and middle schools [10], the school mathematics principles provided by the National Council of Mathematics Teachers have incorporated equity into the standards or principles of mathematics education since the 1990s. The American Mathematical Science Council stated in their statement on active learning that inequality and lack of opportunities for students have been preventing students from learning science, technology, engineering, and mathematics (STEM) subjects after middle school [11]. Similarly, it said that most educators agree that fairness is a worthy goal. However, when the problem is raised, there is very little consensus: How do you think we should solve fairness? [12]. Technical tools alone cannot lead to learning [13]. Instead, learning outcomes are generated from a complex network of socio-technical factors, including ensuring consistent access to hardware and software [14], and focusing on how teachers conceive and implement technology [15], and understand whether and how learners use the technology [16].

Education is a continuous process of knowledge transfer. As an unpredictable public health emergency in the society, online teaching has a huge impact on education and teaching activities in a short period of time. In order to maintain the continuity of education, educators must move the teaching mode from offline to 
online in a very short time. Although online teaching has long been an effective supplement to college education and teaching, its use as the main teaching position has made many. In a short period of time, teachers are at a loss in terms of knowledge reserve or the application of information technology. The educated group is also facing the process of adapting to the transformation of teaching from offline to online, and the educational space from school to home. The school has lost the education scene with complete functions and means, the function of education has become single, and the conventional education method has been lost. Control.

\section{EDUCATIONAL EQUITY IN ONLINE TEACHING}

During the online teaching period, the unfairness presented by education is all-round. Although various colleges and universities actively responded to the Ministry of Education's notice of "no suspension of classes", education is not only about learning professional knowledge, but also guiding students to learn more. Many social attributes have realized the transformation from student to social citizen. Obviously, online education has great limitations at this level.

\subsection{The Impact of Original Family Differences on Students' Home Learning}

First of all, the new digital divide in households is gradually expanding. The previous understanding of the digital divide mainly refers to the information gap and the gap between the rich and the poor caused by the difference in the degree of information and network technology ownership. In our country, the state and governments at all levels have gradually realized the popularization of informatization and shared services through the construction of urban and rural informatization, so the traditional digital divide has gradually been bridged. In addition to the degree of popularization of informatization, the new digital divide has a deep understanding of information technology usage habits and attitudes and the resultant presentation of information technology usage [17]. From the concept of the new digital divide, it is not difficult to see that, based on the differences in knowledge level and cognitive level of different families, information technology usage habits and results presented are completely different. If a simple division is made, knowledge families pay more attention to the learning function of information technology and pass on this influence to family members, while families with low educational background pay more attention to the entertainment function of information technology. This value demand is directly passed on to family members and brings more benefits. Many negative effects. The difference between family information literacy and technical support under the new digital divide leads to the lack of effective support from the information technology literacy environment in the education process of students during online teaching, and the continuity of learning is broken, which directly affects the fairness of the education process of students.

Secondly, the transmission of the family's overall values is an important factor affecting students' home learning. A study in the United States shows that after controlling the growth environment and social relations of students, school education has minimal impact on students, which shows that the role of the family in the education and growth of students is irreplaceable. The support from parents and an undisturbed learning environment, mutual respect among family members, a positive and optimistic attitude, and friendly emotional exchanges are all beneficial to students' home learning. This ideal state is not in every family. It can be found that on the contrary, in such a special stage of online teaching, for families with relatively weak economic conditions, the children's receiving a good education and the improvement of the family's economic control ability are a contradictory and unified combination. The process of 
raising the family's economic level is to some extent accompanied by the transmission of anxiety, the weakening of family care and even the lack of parental roles in the process of student growth. For many families, this economic pressure spreads and magnifies among family members. The link between family socioeconomic status (SES) has a significant relationship with children's academic performance, and in the past few decades in the United States (Hanushek, Peterson, Talpey, \& Woessmann, 2019; Reardon, 2011b) income inequality Expansion hinders the possibility for poor families to use education as an opportunity to change their economic situation. Even if economic factors are ignored, the differences in parental education methods are obvious. Knowledge-based families are more of a growth support role, from learning methods, learning ability improvement, psychological counseling, career planning, etc. Provide students with instructive suggestions, while families with low academic qualifications regard the learning process more as the acquisition of textbook knowledge, and ignore the many growth problems faced by college students. They often use a simple and rude approach to the problems. Way to treat. During online teaching, when the mediating role of schools and teachers is greatly weakened, the contradiction between family education and student growth becomes more obvious and irreconcilable.

\subsection{Online Education Exacerbates the Unfairness of Students' Right to Education}

The foundation of education lies in establishing morality and fostering people, cultivating qualified builders and successors of socialism with comprehensive development of morality, intelligence, physical education, and art. However, current online education is mainly reflected in the development of "intelligence". In addition to intellectual education, moral education Education is generally completed through club activities, internships, second classroom activities, class and dormitory collective construction, family education and online ideological and political education activities cannot meet the needs of moral education. Finland is the country with the most complete education system. When introducing Finnish education, Anderson, the Minister of Education, said that schools are of great significance to the healthy growth of children. It is not only about learning mathematics or specific subjects, but also about schools. An important place for children to socialize with students of the same age and adult teachers. In short, online education will definitely become a very important educational method in the future. It will change the future education pattern with the continuous development of information technology and the continuous innovation of educational concepts. However, based on the educational purpose of cultivating and shaping people, Online education can never replace the traditional education model. Seeking a better integration of online and offline education models under the premise of educational fairness will be the direction of future education development.

\subsection{Online Teaching Affects Special Groups}

The unfairness of education during online teaching is reflected in all levels of student development. For the graduate group, taking the author's school as an example, the initial employment rate of students has decreased by about $20 \%$ compared with previous years. The impact of the shock caused the decrease in recruitment positions. Due to the stagnant cross-regional flow of personnel, students were unable to go out to participate in job interviews, resulting in reduced employment opportunities. For students in economically developed areas, the impact was much smaller. Interregional resource differences between regions (Owens, 2016; Owens, Reardon, \& Jencks, 2016) have become more and more prominent in the huge gap in educational opportunities. Similarly, during the online teaching of mental health education for college students, only some 
group-oriented universal education can be carried out online, and the growth-supporting activities of students with abnormal psychological conditions are forced to stop. A Finnish survey of medical services in Finnish schools during online teaching showed that the utilization rate of medical services in the entire school dropped by $80 \%$. The cessation of medical services does not mean the disappearance of potential problems. How to carry out special planning to eliminate potential problems in a longer period of time in the future and protect the rights of disadvantaged groups to receive education is a problem that educators must seriously consider. When the online and offline education models cannot be fully integrated, the online education model is a double-edged sword. On the one hand, the continuity of education is realized through technical means, and on the other hand, some students cannot enjoy the personality brought by education due to special reasons. The demand for education has expanded the unfairness of education.

\section{ANALYSIS OF THE COMPENSATION STRATEGY OF EDUCATION AFTER RETURNING TO CAMPUS}

At present, Chinese schools have reopened and worked hard to return education and teaching to normal, so as to guarantee the right of all students to return to school to receive education. Educational losses of students during online teaching require educators to scientifically evaluate and implement education compensation measures for a long period of time in the future. At the same time, the large-scale application of online teaching has allowed educators to rethink how online education and offline education will integrate and develop innovatively in the future.

\subsection{Optimized allocation and method innovation of educational resources based on information technology}

It is foreseeable that in the future online education and teaching methods will become an important part of education and play an increasingly important role. By analyzing the use of information technology and existing problems during online teaching, we will continuously improve its functions and use online teaching as an important means to promote educational equity. First, online high-quality education resources are effectively gathered. Online teaching, as an education model with no space restrictions, can improve the quality of teaching through the mode of sharing resources inside and outside the school. First, the school will build an online teaching resource database. The school coordinates excellent teachers in various disciplines to build an expert database, and concentrates the power of excellent teachers to create a golden lesson, which will benefit more students through the radiation effect of information technology. Excellent teachers can be a single teacher or a team of teachers voluntarily, which depends on the teaching experience and the ability to master multimedia technology. To a certain extent, creating a course in the form of a team can better give play to the advantages of each teacher. Second, the education authority takes the lead in optimizing the allocation of educational resources. The ideal approach at this level is to establish a curriculum resource library at the national level. On the one hand, it can reduce costs and resource duplication rate, and on the other hand, it can select high-quality resources from a wider range to improve the quality of courses. In this way, the superior discipline resources of superior schools can benefit other ordinary colleges and universities, and the superior regional educational resources can cover other educationally underdeveloped areas. Second, expand online education management channels with personalized guidance. Another important effect of gathering resources to build a golden lesson is 
to release more human resources. These teacher resources do not mean that they have nothing to do with the education and teaching process, but are more deeply involved in the learning and growth process of students. First of all, as a follow-up teacher to understand the content of the course throughout the course and answer questions about the course. The advantage of online teaching also lies in freeing more students from the constraints of offline classrooms. By increasing the frequency of online interaction, mobilizing the classroom atmosphere to stimulate students' desire for knowledge and a sense of belonging in the classroom, cultivate diversified ways of thinking, and make up for the family. Inadequate education hinders student development Secondly, the interaction between teachers and students in the traditional offline classroom basically ends with the end of the classroom teaching time, while the online mode can effectively make up for this deficiency. Afterschool tutoring can be carried out in a variety of modes Arrange and answer questions, organize group study and discussion, so that students have more opportunities to participate in classroom interaction, which to a certain extent also expands the spatial dimension of education equity. Third, increase investment to provide teachers with digital skills training support. With schools as a unit, a network of "Teachers' Digital Skills Guidance" will be built around the theme of digital teaching, so that these teachers who master the latest technology and methods can tutor other colleagues in their schools to learn and improve their teaching skills together.

\subsection{Develop a Growth Support Plan to Make up for the Educational Loss of Students During Online Teaching}

While advancing the teaching process, colleges and universities should carefully evaluate the loss of education and moral education during the online teaching period, and formulate corresponding compensation plans. First, a course compensation plan that combines group guidance and personalized assistance. Through the final exam performance evaluation, student learning status survey, curriculum practice to fully understand the student learning situation, additional funding support for the lack of professional learning to provide additional teaching resources for students to learn in the fall. On the one hand, teachers of professional courses are arranged to organize knowledge points and answer questions around the courses opened during online teaching, and to improve the combination of theory and practice of students through the establishment of practical courses. Secondly, students have diversity in learning abilities and in-depth knowledge, such as the need to pursue the quality of deep learning and the need to restore credits. Students with different needs have different educational goals and educational methods, so the individualized counseling strategies adopted Also different. Under the control of students' learning pursuits and learning conditions, students are evaluated, and personalized counseling programs are developed to provide them with support services. Second, the moral education compensation plan. Compared with offline, the radiation and effectiveness of online moral education are very limited. As a physical space carrier, the campus has a subtle influence on the growth of students' moral education. The team spirit and organizational planning cultivated by students in the process of participating in activities Social attributes such as social skills are unmatched by online activities. Moral education compensation mainly revolves around the socialist core values, dedication, love of the party and the country implied in public health emergencies to carry out a series of campus cultural and sports activities, and stimulate students' sense of social responsibility, innovation and practical ability through careful activity design. 


\subsection{Develop A Compensation Plan for Special Student Groups}

In the concept of social psychology, a group is a community with similar social and psychological characteristics based on common goals and development processes. According to this concept, college students themselves are a group, and a special group is a relative concept. The development characteristics and needs of the students subdivide many informal student groups. The special group of college students can be summarized as the poor student group, the psychologically abnormal group, the employment difficulty group, the learning difficulty group and so on. With the expansion of college enrollment in recent years, the scale and number of these special groups have shown an expanding trend, which is also a key issue in the current college student management work. The occurrence of online teaching has a significantly higher impact on these special groups than other groups. Taking the psychologically abnormal student group as an example, online teaching has led to the interruption of routine psychological counseling and regular hospital treatment in schools, and a relatively closed environment during the stay at home. It can also lead to a rebound of psychological problems. Therefore, the evaluation and work strategy of special groups will become one of the focuses of the management of college students for a long time. Online teaching has the greatest impact on the employment of graduates. Although graduates have graduated and left school, the employment work requires continuous attention and intervention, whether it is from the aspect of national employment stability, people's livelihood protection, and the employment quality of school graduates. Schools should strengthen the contact with employers, push employment information, and provide employment guidance and assistance.

\section{CONCLUSIONS}

From the "Coleman Report" to the "Education 2030 Framework for Action" of UNESCO, we can see that education equity revolves around three aspects: admission opportunities, educational process, educational results, and recognition of results. In the new crown pneumonia epidemic, due to school closures, students have switched to online learning. For students who lack online learning equipment, some national education departments provide free equipment to borrow, which seems to provide all students with the same enrollment opportunities and education process. However, behind the seemingly equal access to school opportunities and the educational process, due to the students' family support, original learning abilities and tendencies, etc., the form of online learning will aggravate the unfairness of educational results. The large-scale application of online teaching is an opportunity for the development of education in the future. In the face of major public health emergencies, how can innovations in educational technology and educational methods make up for educational losses, especially when the educational differences between regions and families. When it is impossible to make up in a short period of time, the structural injustice of the society must be balanced through additional education compensation. In the final analysis, fair and quality education development needs to be constructed through the overall construction of quality based on fairness, and quality for fairness. The new educational governance system of "in fairness and quality" is gradually realized. This is not only an issue of education fairness, but also an important part of achieving fairness, justice and allround development of Chinese society.

\section{AUTHORS' CONTRIBUTIONS}

Chao Dong, Jing Liu, Jing Jiang, Yu Liu designed research, performed research, analysed recent data and wrote the paper. 


\section{ACKNOWLEDGMENTS}

This research was financially supported by three projects including the Philosophy and Social Sciences Research Project in Universities of Jiangsu Province (No: 2020SJB0153), the Humanity and Social Sciences Research Project of Nanjing Institute of Technology (No: SKLA202017), the Teaching Reform Project of Nanjing Institute of Technology (No: JG2019039).

\section{REFERENCES}

[1] Z. Wu, Written talks on education equity and balan ced development under online teaching, Elementar y Education 3(1) (2020) 32-39.

[2] X. Lei, Analysis of the connotation of contemporar y education equity and its realization methods, Con temporary Educational Science 6(1) (2017) 3-7.

[3] H. Wang, Guarantee the fairness of the education $p$ rocess with reasonable order and rules, Modern Ed ucation Management 4(1) (2009) 17-19.

[4] R.E. Clark, Media will never influence learning, Ed ucational Technology Research and Development 4 2(2) (1994) 21-29. DOI: https://doi.org/10.1007/B F02299088

[5] L. Wood, A. Howley, Dividing at an early age: Th e hidden digital divide in Ohio elementary schools, Learning, Media and Technology 37(1) (2012) 2039. DOI: https://doi.org/10.1080/17439884.2011.5 67991

[6] L. Cuban, H. Kirkpatrick, C. Peck, High access and low use of technologies in high school classrooms: Explaining an apparent paradox, American Educat ional Research Journal 38(4) (2001) 813-834. DOI : https://doi.org/10.3102/00028312038004813

[7] Y. Zhao, K.A. Frank, Factors affecting technology uses in schools: An ecological perspective. Americ an Educational Research Journal 40(4) (2003) 807-
840. DOI: https://doi.org/10.3102/0002831204000 4807

[8] B. Means, M. Bakia, R. Murphy, Learning Online: What Research Tells Us About Whether, When and How, Routledge, 2014.

[9] E.A Hanushek, P.E. Peterson, L.M. Talpey, L. Woe ssmann, The unwavering SES achievement gap: $\mathrm{Tr}$ ends in U.S. student performance (NBER Working Paper No. w25648). Cambridge, MA: National Bur eau of Economic Research, 2019.

[10] A. Owens, Inequality in children's contexts: Incom e segregation of households with and without child ren, American Sociological Review 81(1) (2016) 5 49-574. DOI: https://doi.org/10.1177/0003122416 642430

[11] R. Gutiérrez, Context matters: equity, success, and the future of mathematics education, in: Lloyd GM , Wilsin M, Wilkins JLM, (Eds.), Proceedings of $\mathrm{t}$ he 29th Annual Meeting of the North American Ch apter of the International Group for the Psychology of Mathematics Education, Lake Tahoe, 2007, pp. $1-18$.

[12] H. Cheng, Inequality in basic education in China: A comprehensive review, International Journal of Ed ucational Policies, 3(2) (2009) 81-106.

[13] A.T. Nuyen, Confucianism and the idea of equality , Asian Philosophy, 11(2) (2001) 61-71. https://10. $1080 / 09552360120087840$

[14] E. Oscar, Solving the equity-equality conceptual di lemma: A new model for analysis of the educationa 1 process. Educational Research, 49(4) (2007) 343 363. https://10.1080/00131880701717198

[15] K. Lynch, Research and theory on equality and edu cation, in M. T. Hallinan (Ed.), Handbook of the So ciology of Education, pp. 85-105. Academic Cop. 2 000. 
[16] Y. Chai, L. Yang, An Empirical Analysis of Big D ata on the Fairness of MOOC Education Opportuni ty, Modern University Education 3(1) (2019) 104-1 11.

[17] D. Li, Multidimensionality of Process and Stratific ation of Way Out: A Study on Process Fairness of Chinese University Education, Society 3(1) (2018) 79-104. 